\title{
Survey of stressful life events among diabetic and non- diabetic elderly individuals in Rafsanjan, Iran, in 2015
}

\author{
Ghiyasi M, BSc ${ }^{1}$, Abedi HA, $\mathrm{PhD}^{2 *}$, Khodadadizade A, $\mathrm{MSc}^{3,4}$ \\ 1- MSc Student, Dept. of Nursing, School of Nursing and Midwifery, Isfahan (Khorasgan) Branch, Islamic Azad University, \\ Isfahan, Iran. 2- Professor, Dept. of Nursing, School of Nursing and Midwifery, Isfahan (Khorasgan) Branch, Islamic Azad \\ University, Isfahan, Iran. 3- Lecturer, Academic Member, Dept. of Nursing ,School of Nursing \& Midwifery, Rafsanjan \\ University of Medical Sciences, Rafsanjan, Iran.4- PhD Student in Disaster \&Emergency Health, Shahid Beheshti \\ University of Medical Sciences, Tehran, Iran.
}

Received: April 2016, Accepted: June 2016

Background: Due to the increasing number of stressful life events among the elderly and the rapid spread of diabetes among them, the present study compared the stressful life events of diabetic elderly with those of non-diabetic elderly.

Materials and Methods: This descriptive, cross-sectional study was conducted on 240 senior citizens of over 60 years of age (120 diabetic patients and 120 non-diabetics) of Rafsanjan, Iran. They were chosen through convenience sampling from among visitors of the Diabetes Clinic and Ali Ebne Abitaleb Laboratory in Rafsanjan. The data collection tool used was the questionnaire designed by Pickel et al. This questionnaire consists of two parts; one part is related to demographic information and the other to stressful life events. To analyze the data, Mann-Whitney test, chi-squared, Fisher's exact test, and independent t-test were employed in SPSS software.

Results: The frequency of psychological stresses caused by familial, personal, and environmental factors was higher among the diabetic elderly $(\mathrm{P}<0.05)$. In addition, the frequency of psychological stresses caused by social stressful factors was higher among the non-diabetic elderly. The number of occupational-financial and environmental stressful factors was more among male diabetic patients, and the number of personal stressful factors was more among female patients $(\mathrm{P}<0.05)$. The number of occupational-financial stressful factors was significantly higher among non-diabetic men than women $(\mathrm{P}<0.05)$.

Conclusions: According to the results, stressful factors play a major role in the onset of diabetes.

By recognizing the sources of stress with the assistance of patients, and their family and medical team, effective steps can be taken to prevent and control its probable effects and side effects.

Keywords: Stressful Events, Elderly, Diabetic

\section{Introduction}

Today, the increase in life expectancy has increased the elderly population in all communities (1). Based on life expectancy differences in various countries, the World Health Organization (WHO) has generally defined 60 as the age in which one enters old age (2). As one becomes older, one's health condition goes through some changes. Thus, elderly individuals are under potential threat of some risks such as the probable increase in contagious chronic diseases, loneliness, and lack of social support. Due to mental and physical disabilities, the personal independence of the elderly is under threat in many cases. Therefore, the probability of being diagnosed with diseases and the emergence of disabilities in later periods of life will be increased $(3,4)$.

One of the widespread and disabling diseases among the elderly is diabetes which has different types. Type 1, also called juvenile

\footnotetext{
* Corresponding author: Heidar Ali Abedi, Dept. of Nursing, School of Nursing and Midwifery, Isfahan (Khorasgan) Branch, Islamic Azad University, Isfahan, Iran.

Email: drabediedu@yahoo.com
} 
diabetes, causes the breakdown of beta cell in the pancreas which leads to absolute lack of insulin. Type 2, also called adult-onset diabetes, is a disorder caused by both lifestyle factors and genetics. The role of psychological factors, like stress, in the onset of type 2 diabetes has been the focus of many studies. Furthermore, type 2 diabetes accounts for a considerable amount of government expenses (5). The statistics show that the number of individuals affected by diabetes among 20-79 year olds is 382 million individuals in the world. This number for the same age group in Iran is 4.5 million individuals, and this number also increases in proportion to the number of individuals who live longer (6). Stress is experienced by every person in the modern world. The word stressor refers to those problems and life engagements that have a potentially strong effect on the psychological well-being of adults and may cause stress. Stressful life events are events or experiences that produce severe strain, such as occupational failure, marital separation, and loss of a loved one. Various studies have shown that stressful life events can change one's lifestyle, and are related to physical and psychological health (7). Physiological stress can create exact measurable changes in sympathetic and parasympathetic balance and can activate the hypothalamic-pituitaryadrenal axis. This can cause the secretion of endocrines which then leads to obesity, and consequently, the risk of type 2 diabetes in those who are prone to diabetes. Increase in the level of catecholamines and glucocorticoids, and in turn, activation of the hypothalamic-pituitary-adrenal axis can decrease glucose tolerance (8). In the present study, all stressful life events experienced by both diabetic and non-diabetic elderly were determined using the questionnaire developed by Pickel et al.

Due to the increasing elderly population, the purpose of this study was to present tangible data to decision-makers and families, so that even some small steps could be taken to raise awareness among health care planners, caregivers, and families to reduce such stressful factors, and thus, the rate of diabetes among the elderly.

\section{Material and Methods}

This cross-sectional descriptive study was performed in Rafsanjan, Iran, in 2015. The study sample consisted of all senior citizens of over 60 years of age in Rafsanjan. Based on previous studies, the sample size was determined at 120 subjects per each group (8). That the number of samples was calculated according to the following formula.

$$
\begin{gathered}
n=\left(z_{1}-\frac{\propto}{2}+z_{1}-\beta\right)^{2} \\
* \frac{p_{1}\left(1-p_{1}\right)+p_{2}\left(1-p_{2}\right)}{\left(\mathrm{p}_{2}-\mathrm{p}_{1}\right)^{2}} \\
n=\frac{(10.5) *(0.25+0.21)}{(0.3-0.5)^{2}}=120.75
\end{gathered}
$$

In this formula $\mathrm{P}_{1}$ is the percentage of stressful life events of the diabetic patients $(50 \%), \mathrm{P}_{2}$ the percentage of stressful life events of the non-diabetic patients $(30 \%), \alpha$ is type I error (0.05), and $\beta$ is Type II error (0.10).

The subjects of the study were chosen based some common characteristics like sex, marital status, and age $(\mathrm{P}>0.05)$. The researchers visited the Diabetes Clinic of Rafsanjan City, and by making use of convenience sampling, they chose 120 diabetic patients diagnosed with diabetes by an endocrinologist or specialist. Moreover, the researchers chose 120 non-diabetic patients who visited Ali Ebne Abitaleb Laboratory. All the visits to choose the participants took place over a three-month period. Then, the purpose of the study was explained to those elderly individuals who agreed to participate in the study. The elderly individuals of over 60 years of age who were able to answer the questions were included in the study, and the way to answer the questions was clarified for them. The questionnaires which were left unanswered were excluded from analysis.

The questionnaire designed by Pickel et al. consists of two parts; one part is related to 
demographic information, and the other, which includes 69 items, to stressful life events. The items used in the demographic information form included questions about the age, sex, weight, diabetes history record, family disease history record, and marital status of the participants (8). This questionnaire was administered to a group of college students in 1990, and then, to a group of workers in 1991, and thus, adapted to the Iranian context. The number of options in this Iranian context questioner was less than 69 items. After selecting randomly samples questionnaires were distributed between them. The study conducted by Mohajer et al. showed that the ranking of important life events are not generally very different from those in Pickel et al. (9). The validity of the questionnaire is reported to be 0.82 and the reliability is 0.78 (3). The questions included social and environmental factors (13 items), occupational-financial factors (14 items), familial factors (15 items), and personal factors (27 items).

By choosing either "yes" or "no", the subjects themselves determined the events that they had personally experienced. Next, they chose the events which cause them stress by responding to items on a 5-point Likert scale ( $1=$ none, 2 $=$ little, $3=$ moderately, $4=$ greatly, and $5=$ extremely).

To compare the two groups, the nonparametric Mann-Whitney test was employed since our data were not normally distributed, as some stressful factors did not exist in any of the samples, and so, they received a score of 0 . The normality test was carried out with Kolmogorov-Smirnov test, but the assumption of data normality was rejected. The other statistical tests used to analyze the data in SPSS software (version 18, SPSS Inc., Chicago, IL, USA) included chi-squared, Fisher's exact test, and independent t-test.

\section{Results}

The highest frequency distribution of age in diabetic (88.3\%) and non-diabetic (73.3\%) groups were observed in the individuals in the 65-74 years age group. The average age in the diabetic group was $69.5 \pm 4.5$ and in the nondiabetic group was $71 \pm 6.8(\mathrm{P}<0.05)$. Moreover, $59.2 \%$ of diabetic subjects and $57.5 \%$ of non-diabetic participants were women $(\mathrm{P}>0.05)$. Most of the subjects in both diabetic $(67.5 \%)$ and non-diabetic $(72.5 \%)$ groups were married $(\mathrm{P}>0.05)$. The highest frequency distribution in the diabetic group (58.3\%) was related to those with 4-6 children, and in the non-diabetic group (46.7\%) to the elderly with 7 or more children $(\mathrm{P}>0.05)$. Additionally, the history of diabetes in $40.8 \%$ of diabetic elderly was 5-10 years, and the average history of the disease for the elderly of this group was $9.63 \pm 4.95$ years.

Based on the results of Mann-Whitney test, there was a significant difference between psychological stress caused by social stressful factors, environmental factors, and stressful life events in the elderly of both groups. The mean of stress score caused by social stressful factors was significantly higher among nondiabetic elderly $(\mathrm{P}<0.05)$. The mean of stress score due to financial-occupational, familial, and personal factors was not significantly different among the participants of the two groups $(\mathrm{P}>0.05)$ (Table 1).

Table 1: Comparison of the two groups of the Diabetic and non-diabetic elderly based on the number of stressful factors

\begin{tabular}{ccccc}
\hline & \multicolumn{2}{c}{ Diabetic } & Non-diabetic & Mann-Whitney test \\
\cline { 2 - 4 } & \multicolumn{2}{c}{ Mean \pm SD } & & p-value \\
\hline Social factors & $0.60 \pm 1.03$ & $1.20 \pm 1.48$ & 5490.00 & $<0.001$ \\
\hline $\begin{array}{c}\text { Occupational, welfare, and } \\
\text { financial factors }\end{array}$ & $1.68 \pm 2.07$ & $1.83 \pm 2.78$ & 6722.50 & 0.358 \\
\hline Familial factors & $3.02 \pm 0.76$ & $2.86 \pm 1.55$ & 6604.00 & 0.238 \\
\hline Personal factors & $8.63 \pm 2.99$ & $8.13 \pm 4.00$ & 6562.50 & 0.234 \\
\hline Environmental factors & $5.95 \pm 1.45$ & $3.08 \pm 1.73$ & 1633.00 & $<0.001$ \\
\hline Stressful life events & $19.88 \pm 6.03$ & $17.07 \pm 6.64$ & 5737.50 & 0.006 \\
\hline
\end{tabular}


Table 2: Mean and standard deviation of psychological stress caused by social stressful factors in the two groups

\begin{tabular}{lcc}
\multicolumn{1}{c}{ Stressful event } & \multicolumn{2}{c}{ Diabetic } \\
\cline { 2 - 3 } & \multicolumn{2}{c}{ Mean \pm SD } \\
\hline Jail Sentence & $0.00 \pm 0.00$ & $0.00 \pm 0.00$ \\
\hline Changing the place of residence or moving abroad & $0.32 \pm 0.83$ & $0.28 \pm 0.66$ \\
\hline Changes in the conditions of the place of residence & $0.41 \pm 1.00$ & $0.52 \pm 0.94$ \\
\hline Change in place of residence within the town & $0.35 \pm 0.90$ & $0.51 \pm 0.98$ \\
\hline $\begin{array}{l}\text { Changing the place of residence or moving to } \\
\text { another town }\end{array}$ & $0.19 \pm 0.69$ & $0.40 \pm 0.95$ \\
\hline Aerial bombing & $0.00 \pm 0.00$ & $0.11 \pm 0.48$ \\
\hline Enlisting in the army or war & $0.01 \pm 0.09$ & $0.21 \pm 0.55$ \\
\hline Prosecution due to financial corruption & $0.00 \pm 0.00$ & $0.01 \pm 0.09$ \\
\hline Provisional arrest of a family member & $0.09 \pm 0.58$ & $0.20 \pm 0.79$ \\
\hline Forced change of the place of residence & $0.08 \pm 0.53$ & $0.37 \pm 0.93$ \\
\hline Provisional arrest & $0.00 \pm 0.00$ & $0.00 \pm 0.00$ \\
\hline Summoned to court for legal wrongs & $0.00 \pm 0.00$ & $0.05 \pm 0.34$ \\
\hline Minor breach of law & $0.02 \pm 0.18$ & $0.00 \pm 0.00$ \\
\hline
\end{tabular}

For the diabetic and non-diabetic elderly, the mean of stress score caused by "the changes in the conditions of the place of residence" was higher than other stressful social factors ( $<$ < 0.05). Based on the Likert scale of 0 to 4 , the mean score of this factor for diabetic patients and non-diabetic participants was $0.41 \pm 1.00$ and $0.52 \pm 0.94$, respectively, (Table 2). The mean psychological stress caused by "serious financial problems" for diabetic and nondiabetic elderly was higher than all other occupational-welfare and social stressful events $(\mathrm{P}<0.05)($ Table 3$)$.

Table 3: Mean and standard deviation of psychological stress caused by occupational, welfare, and financial stressful factors in both groups

\begin{tabular}{lcc}
\hline \multicolumn{1}{c}{ Stressful event } & Diabetic & Non-diabetic \\
\cline { 2 - 3 } & \multicolumn{2}{c}{ Mean \pm SD } \\
\hline Serious financial problems & $0.95 \pm 1.74$ & $0.84 \pm 1.43$ \\
Dismissal from employment & $0.00 \pm 0.00$ & $0.08 \pm 0.38$ \\
Career failure & $0.25 \pm 0.95$ & $0.03 \pm 0.27$ \\
Insufficient income & $0.73 \pm 1.50$ & $0.53 \pm 1.12$ \\
Transient unemployment & $0.81 \pm 1.39$ & $0.19 \pm 0.73$ \\
Conflict with a coworker or the boss & $0.01 \pm 0.09$ & $0.14 \pm 0.61$ \\
Changes in occupational conditions & $0.22 \pm 0.79$ & $0.07 \pm 0.32$ \\
Changes in career type and policy & $0.58 \pm 1.18$ & $0.06 \pm 0.27$ \\
Retirement & $0.86 \pm 1.34$ & $0.52 \pm 1.00$ \\
Changes in working hours & $0.33 \pm 0.90$ & $0.13 \pm 0.59$ \\
Taking a heavy bank mortgage & $0.09 \pm 0.58$ & $0.47 \pm 1.00$ \\
Demotion & $0.00 \pm 0.00$ & $0.00 \pm 0.00$ \\
Promotion & $0.00 \pm 0.00$ & $0.02 \pm 0.13$ \\
Moderate financial problems & $0.12 \pm 0.64$ & $0.30 \pm 0.79$ \\
\hline
\end{tabular}

The mean of stress score caused by "hospitalization of a family member" for the diabetic and non-diabetic elderly was higher than any other stressful familial factor $(\mathrm{P}<$
0.05). Based on the Likert scale of 0 to 4 , the mean score of this factor for the diabetic elderly was $3.06 \pm 0.76$ and for the nondiabetic elderly was $1.90 \pm 1.60$ (Table 4). 
Table 4: Mean and standard deviation of psychological stress caused by familial stressful factors in the two

\begin{tabular}{|c|c|c|}
\hline \multirow{2}{*}{ Stressful event } & Diabetic & Non-diabetic \\
\hline & \multicolumn{2}{|c|}{ Mean \pm SD } \\
\hline Spouse betrayal & $0.00 \pm 0.00$ & $0.00 \pm 0.00$ \\
\hline Divorce & $0.00 \pm 0.00$ & $0.07 \pm 0.44$ \\
\hline Hospitalization of a family member & $3.06 \pm 0.76$ & $1.90 \pm 1.60$ \\
\hline Serious row with a family member & $0.03 \pm 0.27$ & $0.38 \pm 0.94$ \\
\hline Child's marriage against parents' will & $0.53 \pm 1.35$ & $0.43 \pm 1.11$ \\
\hline Mounting conflict with spouse & $0.08 \pm 0.46$ & $0.24 \pm 0.73$ \\
\hline Child leaving home over a dispute & $2.53 \pm 1.53$ & $1.27 \pm 1.38$ \\
\hline Conflict with a family member & $0.07 \pm 0.51$ & $0.04 \pm 0.33$ \\
\hline A new member joining the family & $0.07 \pm 0.31$ & $0.05 \pm 0.31$ \\
\hline $\begin{array}{l}\text { Divorce from spouse and separation from } \\
\text { children }\end{array}$ & $0.00 \pm 0.00$ & $0.01 \pm 0.09$ \\
\hline Divorce from spouse with no conflict & $0.00 \pm 0.00$ & $0.01 \pm 0.09$ \\
\hline Mounting conflict with fiancée & $0.08 \pm 0.54$ & $0.01 \pm 0.09$ \\
\hline Child's marriage & $2.23 \pm 0.95$ & $1.10 \pm 0.93$ \\
\hline Child's returning & $0.00 \pm 0.00$ & $0.00 \pm 0.00$ \\
\hline Child leaving for national service & $0.07 \pm 0.49$ & $0.45 \pm 1.04$ \\
\hline
\end{tabular}

The mean stress caused by "death of a family member other than the spouse" for diabetic and non-diabetic elderly was higher than any other stressful personal factor $(\mathrm{P}<0.05)$. As shown by the 5-point Likert scale (0 to 4$)$, the mean score of this factor for the diabetic elderly was $3.61 \pm 0.91$ and for non-diabetic participants was $2.81 \pm 1.46$ (Table 5).

Table 5: Mean and standard deviation of psychological stress caused by personal stressful factors in the two groups

\begin{tabular}{lcc}
\hline & Diabetic & Non-diabetic \\
\cline { 2 - 3 } Stressful event & Mean \pm SD \\
\hline Death of a spouse & $1.28 \pm 1.85$ & $1.11 \pm 1.70$ \\
Death of a child & $0.58 \pm 1.38$ & $1.37 \pm 1.76$ \\
Death of a family member other than the spouse & $3.61 \pm 0.91$ & $2.81 \pm 1.46$ \\
Birth of a child (for mother) & $1.18 \pm 1.11$ & $0.60 \pm 0.98$ \\
Attending an important examination & $0.22 \pm 0.83$ & $0.16 \pm 0.50$ \\
Termination of education (leaving school) & $0.02 \pm 0.13$ & $0.05 \pm 0.29$ \\
The occurrence of an unexpected event & $0.69 \pm 1.32$ & $0.69 \pm 1.20$ \\
Child's engagement & $2.23 \pm 0.87$ & $1.14 \pm 1.21$ \\
Death of a close friend & $3.29 \pm 0.75$ & $1.28 \pm 1.42$ \\
A serious physical illness & $1.39 \pm 1.75$ & $1.26 \pm 1.41$ \\
Birth of a child (for father) & $0.89 \pm 1.18$ & $0.54 \pm 0.98$ \\
Missing something & $0.20 \pm 0.88$ & $0.67 \pm 1.29$ \\
Unintended pregnancy & $0.80 \pm 1.34$ & $0.36 \pm 0.84$ \\
Missing a loved one & $1.77 \pm 1.63$ & $0.62 \pm 1.15$ \\
Menopause & $1.52 \pm 1.54$ & $0.83 \pm 1.09$ \\
Marriage & $0.33 \pm 0.60$ & $0.63 \pm 0.84$ \\
Breaking up with a friend & $0.05 \pm 0.39$ & $0.18 \pm 0.60$ \\
Being diagnosed with a mild physical disease & $1.23 \pm 1.71$ & $1.23 \pm 1.13$ \\
One's engagement & $0.13 \pm 0.41$ & $0.38 \pm 0.70$ \\
Termination of education & $0.15 \pm 0.54$ & $0.01 \pm 0.09$ \\
Intended pregnancy & $1.29 \pm 1.34$ & $0.53 \pm 0.89$ \\
Failure in education & $0.00 \pm 0.00$ & $0.14 \pm 0.57$ \\
Starting school (part time or full time) & $0.04 \pm 0.30$ & $0.02 \pm 0.13$ \\
Breaking off engagement & $0.00 \pm 0.00$ & $0.03 \pm 0.26$ \\
Wife's pregnancy & $0.37 \pm 0.83$ & $0.28 \pm 0.74$ \\
Abortion or stillbirth & $0.90 \pm 1.39$ & $0.65 \pm 1.24$ \\
Changing school & $0.03 \pm 0.26$ & $0.01 \pm 0.09$ \\
\hline
\end{tabular}


Table 6: Mean and standard deviation of psychological stress caused by environmental stressful factors in the

\begin{tabular}{|c|c|c|}
\hline \multirow{2}{*}{ Stressful event } & Diabetic & Non-diabetic \\
\hline & \multicolumn{2}{|c|}{ Mean \pm SD } \\
\hline Rising prices of essential commodities & $3.07 \pm 1.00$ & $2.30 \pm 1.33$ \\
\hline Unemployment (or an unacceptable job) & $1.03 \pm 1.73$ & $0.68 \pm 1.26$ \\
\hline Problems of renting a house & $0.07 \pm 0.46$ & $0.02 \pm 18$ \\
\hline Standing in long queues for the bus & $3.21 \pm 0.88$ & $0.56 \pm 1.04$ \\
\hline Lack of medical specialists and medicine & $3.28 \pm 0.99$ & $1.42 \pm 1.55$ \\
\hline Addiction & $0.48 \pm 1.21$ & $0.11 \pm 0.53$ \\
\hline Marital problems & $0.10 \pm 0.63$ & $0.18 \pm 0.67$ \\
\hline Stress and discomfort at the work place & $0.60 \pm 1.21$ & $0.23 \pm 0.72$ \\
\hline Traffic & $1.28 \pm 1.62$ & $0.04 \pm 0.30$ \\
\hline Air pollution & $0.59 \pm 1.27$ & $0.11 \pm 0.41$ \\
\hline $\begin{array}{l}\text { Failure of child(ren) in the university } \\
\text { entrance examination }\end{array}$ & $3.14 \pm 1.33$ & $1.00 \pm 1.50$ \\
\hline $\begin{array}{l}\text { Lack of educational settings like primary } \\
\text { or high school }\end{array}$ & $0.37 \pm 1.04$ & $0.15 \pm 0.64$ \\
\hline Lack of sport and recreational facilities & $2.35 \pm 1.39$ & $0.84 \pm 1.25$ \\
\hline
\end{tabular}

Among the diabetic elderly, a greater amount of psychological stress stemmed from "lack of medical specialists and medicine" than the other stressful factors attributed to the environment. Among the non-diabetic elderly, the mean stress caused by "rising prices of essential commodities" was higher than the other environmental stressful factors $(\mathrm{P}<$ 0.05) (Table 6). As the findings presented in table 7 show, based on Mann-Whitey test, there was a significant difference between the number of stressful factors in the elderly of the two groups $(\mathrm{P}>0.05)$, and the number of social stressful factors was significantly higher among the non-diabetic elderly. MannWhitney test also showed that the number of environmental stressful factors was significantly higher among the diabetic elderly than the non-diabetic elderly $(\mathrm{P}>0.05)$. Generally, the total number of stressful life events was significantly higher among diabetic than non-diabetic elderly $(\mathrm{P}>0.05)$.

Table 7: Comparison of the two diabetic and non-diabetic elderly groups based on the number of stressful factors

\begin{tabular}{|c|c|c|c|c|}
\hline & Diabetic & Non-diabetic & \multirow{2}{*}{$\begin{array}{l}\text { Mann-Whitney } \\
\text { test statistics }\end{array}$} & \multirow{2}{*}{ p-value } \\
\hline & \multicolumn{2}{|c|}{ Mean \pm SD } & & \\
\hline Social factors & $0.60 \pm 0.09$ & $1.20 \pm 0.13$ & 5490.00 & $<0.001$ \\
\hline $\begin{array}{l}\text { Occupational-financial } \\
\text { factors }\end{array}$ & $1.68 \pm 0.19$ & $1.83 \pm 0.25$ & 6722.50 & 0.358 \\
\hline Familial factors & $3.03 \pm 0.07$ & $2.86 \pm 0.14$ & 6604.00 & 0.238 \\
\hline Personal factors & $8.63 \pm 0.27$ & $8.13 \pm 0.37$ & 6562.50 & 0.234 \\
\hline Environmental factors & $5.95 \pm 0.13$ & $3.08 \pm 0.16$ & 1633.00 & $<0.001$ \\
\hline Stressful life events & $19.88 \pm 0.55$ & $17.09 \pm 0.61$ & 5737.50 & 0.006 \\
\hline
\end{tabular}

In the diabetic group, the number of occupational-financial stressful factors and environmental stressful factors was significantly higher among men than women $(\mathrm{P}>0.05)$. The number of personal stressful factors was significantly higher among women than men $(\mathrm{P}>0.05)$. In the non-diabetic group, the only significant difference between men and women was in the number of occupational-financial stressful factors which was significantly higher among men than women $(\mathrm{P}>0.05)$ (Table 8$)$. 
Table 8: Comparison of the two groups of diabetic and non-diabetic elderly based on the number of stressful factors and sex

\begin{tabular}{|c|c|c|c|c|c|}
\hline & \multirow{2}{*}{ Sex } & Diabetic & \multirow{2}{*}{ p-value* } & Non-diabetic & \multirow{2}{*}{ p-value } \\
\hline & & Mean \pm SD & & Mean \pm SD & \\
\hline \multirow{2}{*}{ Social factors } & Female & $0.51 \pm 0.10$ & \multirow{2}{*}{0.760} & $1.19 \pm 0.18$ & \multirow{2}{*}{0.821} \\
\hline & Male & $0.73 \pm 0.18$ & & $1.22 \pm 0.20$ & \\
\hline \multirow{2}{*}{$\begin{array}{l}\text { Occupational- } \\
\text { financial factors }\end{array}$} & Female & $1.15 \pm 0.19$ & \multirow{2}{*}{0.003} & $1.13 \pm 0.15$ & \multirow{2}{*}{$<0.001$} \\
\hline & Male & $2.43 \pm 0.35$ & & $2.76 \pm 0.54$ & \\
\hline \multirow{2}{*}{ Familial factors } & Female & $2.97 \pm 0.08$ & \multirow{2}{*}{0.433} & $2.83 \pm 0.19$ & \multirow{2}{*}{0.868} \\
\hline & Male & $3.10 \pm 0.12$ & & $2.90 \pm 0.20$ & \\
\hline \multirow{2}{*}{ Personal factors } & Female & $9.51 \pm 0.36$ & \multirow{2}{*}{$<0.001$} & $8.61 \pm 0.50$ & \multirow{2}{*}{0.134} \\
\hline & Male & $7.37 \pm 0.35$ & & $7.49 \pm 0.51$ & \\
\hline \multirow{2}{*}{$\begin{array}{l}\text { Environmental } \\
\text { factors }\end{array}$} & Female & $5.58 \pm 0.16$ & \multirow{2}{*}{0.002} & $2.94 \pm 0.20$ & \multirow{2}{*}{0.596} \\
\hline & Male & $6.49 \pm 0.21$ & & $3.25 \pm 0.25$ & \\
\hline \multirow{2}{*}{ Stressful life events } & Female & $19.72 \pm 0.65$ & \multirow{2}{*}{0.849} & $16.70 \pm 0.86$ & \multirow{2}{*}{0.621} \\
\hline & Male & $20.12 \pm 0.98$ & & $17.63 \pm 0.84$ & \\
\hline
\end{tabular}

*Mann Whitney Test

\section{Discussion}

The findings revealed that the occupationalwelfare-financial stressful factor with the highest frequency in both groups was retirement, and the frequency of this factor was higher among diabetic individuals than non-diabetic subjects. Based on previous studies, as one's income declines, the quality of one's life also declines, and ill elderly individuals will face serious difficulties. On the other hand, the cost of medical care increases annually in Iran; therefore, senior citizens have difficulty in providing their medical care costs. Inappropriate employment for housewives and retired individuals, and also their low economic status, and lack of financial support have all created many issues for our honored senior citizens, especially those suffering from diabetes. The amount and type of physical activity are effective in decreasing insulin tolerance. The findings of the present study are in line with those by Malek et al. (10-14).

Since in Iranian communities more than $90 \%$ of the elderly are looked after by their children, family support is one of the most important factors in the partial improvement of the health condition of the elderly patient. Most of the stressful factors in the late adulthood period are of the nature of "missing", like missing a child or spouse, and child's imprisonment or marriage, which are the most stressful events in the life period of an elderly (14). Moreover, based on the findings of the present study, the familial stressful factor with the highest frequency among the elderly of both groups was "children's marriage and engagement", and the high frequency of this factor was more significant among diabetic patients than nondiabetic participants $(\mathrm{P}<0.05)$.

Considering the fact that the economic situation of the society has a direct influence on the creation of anxiety, depression, and behavioral disorders, the sudden daily increase in prices can cause mental anxiety, psychological stress, and economic pressure in the society. Therefore, there is a significant correlation between economic status and blood sugar control. Those who had better financial situation had more regular check-ups so there blood sugar was better. As the findings show, the most frequent environmental stressful factor among the elderly of both groups was "rising prices of essential commodities" like food, and its frequency was higher among diabetic patients $(\mathrm{P}<0.05)$. The findings of this study are in agreement with the findings of studies by Novak and Shiri Mohammadi (712). 
The present investigation also showed that mean psychological stress caused due to "death of a family member other than the spouse" for the diabetic and non-diabetic elderly was higher than any other personal stressful factor $(\mathrm{P}<0.05)$. When an elderly adult is grieved by the loss of a loved one, he/she is coping with the most stressful life event they will experience throughout their life, and this leaves the individual in the worst condition possible. They feel defeated and frustrated and have no hope of the future. Thus, the social support provided by the companions of the elderly is undeniably important. The mean stress caused by the death of a family member other than the spouse for the diabetic and non-diabetic elderly was higher than any other personal stressful factor. This finding is in line with the results reported by Aghanouri (10).

On the other hand, the social stressful factor with the highest frequency in both groups was "changes in conditions of place of residence". Changes in the conditions of the place of residence of the elderly have different physiologic, economic, social, welfare, and communication aspects. Each of these factors has an influential effect on the health status and well-being of the elderly (8-15).

In the diabetic group, the number of occupational-financial stressful factors and environmental factors was significantly higher among men than women, and this is in agreement with the results of other studies (16). Based on the results of Mann-Whitney test, the total number of stressful life events among diabetic elderly was significantly higher than those among non-diabetic elderly $(P>0.05)$, which is in line with the findings of other studies (17).

Therefore, it can be claimed that the most prominent effect of stressful factors has been on diabetic patients, and it is probably the high frequency and high intensity of such factors that cause the development of diabetes in elderly adults. Most elderly individuals experience at least one physical or mental illness. Diabetes, high blood pressure, dementia, and cardiovascular diseases are some examples of physical diseases, whereas stress, depression, and anxiety are the common mental diseases of this critical life period. A multitude of stress-producing factors weakens the immune system, and thus, causes a decrease in the quality of life (QOL) of the elderly. QOL and health status are of such importance that experts believe that health care in the present century should aim at improving QOL and developing a well-thought approach to expand the definition of health to the extent that it includes all areas of physical, psychological, and social welfare.

\section{Conclusion}

The findings of this study showed that the mean of all stressful factors among diabetic individuals was higher than non-diabetic individuals. Keeping diabetes under control requires general planning to reduce the effects of social factors which cause the disease. Therefore, by presenting the results of this study to health care authorities of the society, we can take effective steps to decrease the spread of this disease. On the other hand, by considering the underlying factors which might lead to the emergence of diabetes, like psychological factors, and by administering psychological treatment along with pharmacotherapy, we can lower the intensity of diabetes and protected the individual against stressful factors. As diabetes treatment in most countries is administered with a team-based approach, we should take actions to control the spread of the disease with the assistance of patients themselves, their families, and health care teams. Today, the role of education in disease control and prevention is recognized; therefore, training and education in the form of encouraging optimism and stress-control strategies should be applied to teach patients to cope with late adulthood problems. When developing general plans, it is suggested that training and education based on the needs of the patients, their families, and health care professionals be taken into consideration. 
It is recommended that the present study be replicated by including more participants and expanding the scope of the study to recognize more stressful factors and life engagements of the elderly. Furthermore, it is suggested that a qualitative study with interviews and openended questions focusing on stressful life factors of diabetic patients be carried out. Making use of the results of such a study can considerably help health care planners in reducing the spread of this disease.

One of the limitations of the present study was the unwillingness of some of the participants to cooperate with the researcher which was mainly due to painful memories, illiteracy or low literacy, and physical incapability because of their old age. To eliminate this limitation, other subjects were substituted.

\section{Acknowledgment}

The present article was written based on the Master's thesis approved by Islamic Azad University, Isfahan (Khorasgan branch), with the ethics code IR.MUI.REC.1394.4.41ld. I should express my sincere gratitude to all professors and colleagues who helped me throughout this research project. In addition, my special thanks go to all those dear senior citizens who passionately opened their hearts to me and cooperated with me.

\section{Conflict of Interest: None declared}

\section{References}

1. Amirideloye M. Comparison of urban and rural elderly support needs Gonabad city [MSc thesis]. Isfahan: Isfahan (Khorasgan) Branch, Islamic Azad University; 2014.

2. Akbari kamrani AA. Memory and cognition in aging. $2^{\text {nd }}$ ed. Tehran: University of Social Welfare and Rehabilitation Sciences; 2010. P.310.

3. Borhaninejad V, Momenabadi V, Hossseini Sh, Mansori T, Sadeghi A, toroski M. Health physical and mental status in the elderly of Kerman. Journal of North Khorasan University of Medical Sciences 2015; 6(4):715-25.

4. Bastani F, Pourmohammadi A, Haghani H. Relationship between perceived stress with spiritual health among older adults with diabetes registered to the association of diabetes prevention and control in Babol, 2013. Journal of Hayat 2014; 20(3):6-18.

5. Aghamohamadian H, Ghanbari B, Vaezy M. Comparative exploration of stressors and coping strategies in diabetic and non-diabetic subjects. Journal of Sabzevar University of Medical Sciences 2010; 17(1):27-32.

6. Polonsky WH, Fisher L, Hessler D, Johnson N. Emotional distress in the partners of type 1 diabetes adults: worries about hypoglycemia and other key concerns. Diabetes Technol Ther 2016; 18(5):292-7.

7. Shiri Mohammadabadi A, Yazdkhasti F, Dadgari A. Determining the major stressful events in elderly people and their relation with depession and cognitive decline. The Journal of Toloo-e-Behdasht 2014; 13(6):139-51.

8. Maksimovic JM, Vlajinac HD, Pejovic BD, Lalic NM, Vujicic IS, Maksimovic MZ, et al. Stressful life events and type 2 diabetes. Acta Clin Belg 2014; 69(4):273-6.

9. Baghri F, Aloudari M, Aboutalebi Sh, Asgharnezhad Farid AA. Comparison of stressors and coping strategies between patients with somatization disorder and non-patient counterparts. Thought and Behavior in Clinical Psychology 2012; 6(24):39-48.

10. Agha nouri A, Mahmoudi M, Salehi H, Jafarian K. Quality of life in the elderly people covered by health centers in the urban areas of Markazi Province, Iran. Iranian Journal of Ageing 2012; 6(4):20-9.

11. dehkordi S. Compare prospects when the positive and negative happiness and psychological well-being in the elderly, employed and unemployed in Isfahan [MSc thesis]. Isfahan: Isfahan (Khorasgan) Branch, Islamic Azad University; 2014.

12. Novak M, Bjorck L, Giang KW, Heden-Stahl C, Wilhelmsen L, Rosengren A. Perceived stress and incidence of Type 2 diabetes: a 35-year follow-up study of middle-aged Swedish men. Diabet Med 2013; 30(1):e8-16.

13. Rezvani MR, Mansourian H, Ahmadadadi H, Ahmadabadi F, Parvai Here-Dasht S. An assessment on factors affecting the quality of life of elderly in rural regions (Case study: neishabour county). Journal of Rural Research 2013; 4(2):301-26.

14. Malek A, Dadashzadeh H, Porafkari N, Safaeyan A. Ranking of stressful life events in the general population Tabriz. Medical Journal of Tabriz University of Medical Scienes and Health Services 2008; 30(4):73-80.

15. Nam S, Chesla C, Stotts NA, Kroon L, Janson SL. Barriers to diabetes management: patient 
and provider factors. Diabetes Res Clin Pract 2011; 93(1):1-9.

16. Hatamloo Sadabadi M, Babapour Kheirodin J. Comparison of quality of life and coping strategies in diabetic and non diabetic people. Journal of Shahid Sadoughi University of Medical Sciences 2013; 20(5):581-92.
17. Karimi S, Jaafari A, Ghamari M, Esfandiary M, Salehi Mazandarani F, Daneshvar S, et al. A Comparison of type II diabetic patients with healthy people: coping strategies, hardiness, and occupational life quality. Int J High Risk Behav Addict 2016; 5(1):e24169. 